\title{
Comorbidities and related factors in rheumatoid arthritis patients of south India- Karnataka Rheumatoid Arthritis Comorbidity (KRAC) study
}

\author{
S. Chandrashekara ${ }^{1}$, V. Shobha' ${ }^{2}$, B.G. Dharmanand ${ }^{3}$, R. Jois ${ }^{4}$, S. Kumar ${ }^{5}$, \\ K.M. Mahendranath ${ }^{6}$, V. Haridas ${ }^{7}$, S. Prasad ${ }^{8}$, Y. Singh ${ }^{9}$, M.A. Daware ${ }^{10}$, \\ A. Swamy ${ }^{11}$, R. Subramanian ${ }^{12}$, S.A. Somashekar ${ }^{13}$, A.M. Shanthappa ${ }^{14}$, \\ K.R. Anupama ${ }^{1}$
}

${ }^{1}$ ChanRe Rheumatology and Immunology Center, Bangalore, India; ${ }^{2} S t$. John's Medical College Hospital, Bangalore, India; ${ }^{3}$ Sakra Hospital, Bangalore, India; ${ }^{K}$ Kanva Diagnostics Center, Bangalore, India; ${ }^{5}$ Columbia Asia Hospital, Bangalore, India; ${ }^{6}$ Samarpan Health Centre, Bangalore, India; ${ }^{7}$ Arthritis Superspeciality Center, Hubli, India; ${ }^{8}$ Vikram Hospital Pvt Ltd., Mysore, India; ${ }^{9}$ Manipal Hospital, Bangalore, India; ${ }^{10}$ Narayana Health City, Bangalore, India; ${ }^{11}$ Anurag Clinic, Bangalore, India; ${ }^{12}$ Rheumatology Clinic, Bangalore, India; ${ }^{13}$ Bangalore Rheumatology Center, Bangalore, India; ${ }^{14}$ Arushi Rheumatology Center, Tumkur, India

\begin{abstract}
SUMMARY
The aim was to study the prevalence of comorbidities in rheumatoid arthritis (RA) patients in everyday clinical practice and their association with disease-specific and demographic factors.

The multi-center study recruited 3,247 (at 14 centers, and 265) were excluded due to incomplete data. The number of subjects considered for the analysis was 2982 . The mean ( \pm standard deviation) age was $48.98 \pm 12.64$ years and the male-to-female ratio was 1:5. The data was collected based on a pre-structured pro forma by trained clinical research associates through interview and verification of charts and reports available in the patient records. The following comorbidities were studied: cardiovascular disease, hypertension, diabetes mellitus, hypercholesterolemia, thyroid disease, psychiatric diseases like depression, and pulmonary disease. Hypertension (20.7\%), diabetes mellitus (14.4\%) and thyroid disease (18.3\%) were the most prevalent comorbidities. Hypercholesterolemia (5.3\%), pulmonary diseases (2.1\%), cardiovascular diseases $(0.2 \%)$ and depression $(0.03 \%)$ were prevalent in $\leq 5 \%$ of the study population. The overall presence of comorbidity increased with age and reduced with the duration of illness prior (DOIP). The age, gender, and DOIP differed significantly between groups with and without hypercholesterolemia. Females had a statistically increased prevalence of thyroid disease.

The prevalence of comorbidities in RA patients from south India is around $40 \%$ and the incidence of comorbidity increased with age. As per the literature evidence, the prevalence in the current study subjects was higher when compared to prevalence of similar diseases occurring in the general south Indian population.
\end{abstract}

Key words: Rheumatoid arthritis; Comorbidities; Cardiovascular disease; Hypertension; Diabetes mellitus; Hypercholesterolemia; Thyroid disease.

Reumatismo, 2017; 69 (2): 47-58

\section{INTRODUCTION}

heumatoid arthritis (RA), a chronic debilitating autoimmune disorder affecting multiple joints, is associated with reduced life expectancy. Comorbidities in RA are defined as one or more additional disorders (or diseases) associated with a primary disease (1). Prevalence of comor- bid conditions with RA vary across different countries from $3 \%$ to $60 \%(2,3)$. However, certain studies have reported a high prevalence (up to $80 \%$ ) of one or more comorbid conditions (4). Effective management of RA has improved the survival rate, but the presence of associated comorbidity has a negative impact on the outcome (5$8)$. In addition, the comorbidities influence
Corresponding author S. Chandrashekara ChanRe Rheumatology and Immunology Center, $149,15^{\text {th }}$ main, NHCL water tank Road, $4^{\text {th }}$ Block, $3^{\text {rd }}$ stage, Basaweswaranagar, Bangalore 560079, India E-mail: chandrashekara_s@yahoo.com 
the treatment choice, outcome, and quality of life and pose major challenges in the adoption of management strategies of RA $(9,10)$. Hence, the data on comorbidity and the associated factors could be beneficial in customizing the management strategies and identifying determinants of comorbidity. There is limited literature evidence from India pertaining to comorbidities in RA. Recognizing the lacunae, Karnataka chapter of Indian Rheumatology Association had organized a cross-sectional study titled Karnataka Rheumatoid Arthritis Comorbidity study (KRAC) primarily to collect the data on prevalence of comorbidities in RA patients. The study was also intended to evaluate the demographic characteristics and factors influencing the comorbidities such as age, gender, and duration of the disease. The comorbidities studied included diabetes mellitus (DM), hypertension (HTN), cardiovascular disease (CVD), thyroid disease, hypercholesterolemia, psychiatric diseases such as depression, bronchial asthma, and chronic obstructive pulmonary disease (COPD) classified under pulmonary diseases (PD).

\section{PATIENTS AND METHODS}

The observational, cross-sectional, multicentric study was conducted at 14 centers across Karnataka (India), from September 2014 to July 2015, as part of KRAC, under the supervision of rheumatologists. The participation was voluntary and the study centers involved both academic and nonacademic rheumatology specialty units. The study was approved by the ethics committee of the respective institutions and there was adequate representation of centers across the state of Karnataka. Subjects above 18 years of age, who fulfilled the 2010 American College of Rheumatology/ the European League against Rheumatism (EULAR) classification criteria for RA, were enrolled in the study by the cluster sampling method (11). Consecutive patients who consented to participate in the study were recruited from each center on the specified days. The data was collected based on a pre-structured pro forma as an interview by trained clinical research associates, and involved verification of charts and reports available in the patient records. Patients' disease activity was assessed using the 28-joint disease activity score based on erythrocyte sedimentation rate (DAS-28 ESR) and the medication history for each patient was also obtained. Patients' demographic data collected included duration of illness prior (DOIP): duration of symptoms related to RA prior to the first visit to rheumatologist/diagnosis, and duration of follow-up (DOF) with rheumatologist: duration of patient follow-up with rheumatologist. The total duration of disease (TOD) was the sum of DOIP and DOF. The study evaluated the following comorbidities: CVD including myocardial and cerebrovascular ischemia, infarction and stroke, HTN, DM, hyperlipidemia, thyroid disease, psychiatric diseases like depression, and PD (bronchial asthma and COPD). The details of disease variables related to comorbidity were also collected.

The patients meeting the American Diabetes Association (ADA) criteria were considered to have DM. Subjects not on regular anti-diabetic medication were classified based on the verification of either blood sugar or glycated hemoglobin report. The patients who were diagnosed to have bronchial asthma and using inhalers, or diagnosed to have COPD, were categorized under PD. Interstitial lung disease without any previous PD was considered as an extra-articular feature and not as a comorbidity. However, patients who had both were counted in both the events. The patients were examined for the presence of any clinical symptoms related to the cardiovascular events. The status of cardiovascular disorders was determined through recollection or self-declaration. In subjects with positive ECG finding, echocardiography or any other proof of specific diagnosis was considered. The patient was classified to have HTN if she/he had a confirmed diagnosis and was on anti-hypertensive/s. The patient was considered to be suffering from dyslipidemia (hypercholesterolemia) if total cholesterol was $>240 \mathrm{mg} / \mathrm{dL}$ and triglyceride $>200 \mathrm{mg} / \mathrm{dL}$ based on NCEP 
guidelines with the test performed within 6 months before recruitment, or was managed by a cholesterol lowering drug based on a previous assessment (12). The status was considered unknown if the test was not performed. Patients with abnormal thyroid function test (TFT) or on replacement therapy were classified as having thyroid disease. Subjects were classified as normal or abnormal based on the TFT test and those without the test findings were marked as status unknown. The psychiatric disorders such as depression were noted only if the patient was diagnosed with the disease and needed regular psychiatrist consultation. The independent variables considered for the analysis of prevalence of comorbidity were: age, gender, smoking history, DOIP, DOF with rheumatologist, TOD, and type of combination of disease-modifying antirheumatic drugs (DMARDs) used. The age was grouped into: $<30$ years, $30-39$ years, 40-49 years, $50-59$ years, and $\geq 60$ years. The DOIP was classified as: $\leq 6$ months, 6 months-2 years, 2-10 years, and $>10$ years. The treatment was grouped as single, double, triple and four drugs DMARD combinations. The TOD and DOF were taken as continuous variables. The presence or absence of comorbidity was taken as a dependent variable and analyzed separately for all the comorbidities. Occurrence of any one of the comorbidities was assessed separately as presence of comorbidity. The groups were compared for demographic and clinical characteristics, and drug usage by Mann-Whitney U test for continuous variables and chi-square for categorical variables. Fisher's exact test, instead of chi-square, was used wherever the number of the expected count was $<5$. Univariate logistic regression was performed to measure the association between the dependent variables and the independent variables. $p$ value $\leq 0.2$ was considered as the cut-off for inclusion of variables in multivariate analysis. A multivariate logistic regression was performed to verify the factors associated with the RA patients having comorbidity. Univariate and multivariate analyses were performed for presence of any comorbidity and for each of the comorbid conditions noted in the study. The $95 \%$ confidence interval was noted and $\mathrm{p}$ value $<0.05$ was considered significant. The age group $<30$ years, male gender, non-smoker, DOIP $\leq 6$ months and single DMARD were considered as reference groups for the logistic regression analysis. Statistical Package for the Social Sciences (SPSS 22) was used for statistical analysis.

\section{RESULTS}

The multi-center study recruited 3247 subjects at 14 centers, out of whom 265 patients were excluded due to incomplete data. The total sample size considered to assess the presence of comorbidity was 2982. The number of cases considered for each comorbidity was: PD: 2981, CVD: 2949, DM: 298, HTN: 2980, hypercholesterolemia: 1827, and thyroid illness: 1992. However, psychiatric disorders were not included for analysis as there was only one patient $(0.03 \%)$. The mean ( \pm standard deviation) age of the total number of study participants (2982) was $48.98 \pm 12.64$ and the male-to-female ratio was $1: 5$. The median TOD was 48 (0.5-492) months. The corresponding median DOIP and DOF were 12 (0.2-470) months and 24 (0-484) months. Among the 2294 (76.9\% of the total) subjects tested, $1955(85.2 \%)$ were positive for rheumatoid factor (RF). Six hundred and sixty-eight patients were considered undetermined due to the unavailability of test reports. Anti-citrullinated protein antibody (ACPA) positivity was reported in $246(79.1 \%)$ out of the $311(10.43 \%$ of the total) tested subjects. The proportion of patients with one or more comorbidities was $40.3 \%(n=1203)$. The corresponding percentages of subjects with one, two, three, and four comorbidities were $25.65 \%$ $(\mathrm{n}=765), 9.36 \% \quad(\mathrm{n}=279), 2.21 \% \quad(\mathrm{n}=66)$, and $0.44 \%(n=13)$. The descriptive characteristics of study subjects with diverse comorbidities are given in Tables I and II. Majority of the patients were treated with double DMARDs. The single DMARDs given to patients were: methotrexate $(9.4 \%)$ hydroxychloroquine $(4.4 \%)$, leflunomide $(0.8 \%)$, and sulfasalazine $(0.2 \%)$. The com- 
monly used double DMARD combination was methotrexate and hydroxychloroquine $(60.7 \%)$, followed by methotrexate-leflunomide (3.4\%), hydroxychloroquine-leflunomide $(2.6 \%)$, methotrexate-sulfasalazine $(0.8 \%)$, hydroxychloroquine-sulfasalazine $(0.8 \%)$, and leflunomide-sulfasalazine $(0.03 \%)$. The triple drug combination comprised of methotrexate, hydroxychloroquine along with leflunomide $(10.8 \%)$ or sulfasalazine $(2.5 \%)$. Four drug combination included methotrexate, hydroxychloroquine, leflunomide, and sulfasala- zine $(0.2 \%)$. Very few subjects received D-penicillamine, azathioprine, cyclosporine/tacrolimus, mycophenolate and other DMARDs as triple/four drug combinations. Three hundred and nineteen $(10.7 \%)$ patients had received biologics and none were on active treatment with biologics at the time of study. Hence biologics were not considered for analysis.

The comparison of demographic and clinical characteristics of RA subjects with and without comorbidities is given in Tables I and II. Significant difference with re-

Table I - Descriptive characteristics of rheumatoid arthritis patients with comorbidity, bronchial asthma and chronic obstructive pulmonary disease, chronic heart failure and diabetes mellitus.

\begin{tabular}{|c|c|c|c|c|c|c|c|c|c|c|c|c|c|}
\hline \multirow[b]{2}{*}{ Variables* } & \multirow[b]{2}{*}{ Groups } & \multicolumn{3}{|c|}{ Comorbidity (n=2982) } & \multicolumn{3}{|c|}{$\mathrm{PD}(\mathrm{n}=2981)$} & \multicolumn{3}{|c|}{ CVD $(n=2949)$} & \multicolumn{3}{|c|}{ DM (n=2982) } \\
\hline & & No & Yes & $p$ value & No & Yes & $p$ value & No & Yes & $\begin{array}{c}p \\
\text { value }\end{array}$ & No & Yes & $\begin{array}{c}p \\
\text { value }\end{array}$ \\
\hline \multirow{5}{*}{$\begin{array}{l}\text { Age groups } \\
\text { (years) }\end{array}$} & $<30$ & $141(62.4)$ & $85(37.6)$ & \multirow{5}{*}{$<0.001$} & 222(98.2) & $4(1.8)$ & \multirow{5}{*}{0.032} & $221(99.5)$ & $1(0.5)$ & \multirow{5}{*}{0.089} & $200(88.5)$ & $26(11.5)$ & \multirow{5}{*}{0.001} \\
\hline & $30-39$ & $319(68.5)$ & $147(31.5)$ & & 462(99.4) & $3(0.6)$ & & $457(99.3)$ & $3(0.7)$ & & 420(90.1) & $46(9.9)$ & \\
\hline & $40-49$ & $482(62.7)$ & $287(37.3)$ & & $754(98)$ & $15(2)$ & & $761(99.9)$ & $1(0.1)$ & & $662(86.1)$ & $107(13.9)$ & \\
\hline & $50-59$ & $493(56.9)$ & $374(43.1)$ & & $848(97.8)$ & 19(2.2) & & $854(99.9)$ & $1(0.1)$ & & $739(85.2)$ & $128(14.8)$ & \\
\hline & $\geq 60$ & $344(52.6)$ & $310(47.4)$ & & $632(96.6)$ & $22(3.4)$ & & $650(100)$ & $0(0)$ & & $532(81.3)$ & $122(18.7)$ & \\
\hline \multirow{2}{*}{ Gender } & Male & $279(60.1)$ & $185(39.9)$ & \multirow{2}{*}{0.822} & $453(97.6)$ & $11(2.4)$ & \multirow{2}{*}{0.725} & $457(99.8)$ & $1(0.2)$ & \multirow{2}{*}{1.000} & $391(84.3)$ & $73(15.7)$ & \multirow{2}{*}{0.368} \\
\hline & Female & $1500(59.6)$ & 1018(40.4) & & $2465(97.9)$ & $52(2.1)$ & & $2486(99.8)$ & $5(0.2)$ & & $2162(85.9)$ & $356(14.1)$ & \\
\hline \multirow{2}{*}{$\begin{array}{l}\text { Smoking } \\
\text { status }\end{array}$} & $\begin{array}{l}\text { Non- } \\
\text { Smoker }\end{array}$ & $1738(59.7)$ & $1175(40.3)$ & \multirow{2}{*}{0.968} & 2853(98) & $59(2)$ & \multirow[t]{2}{*}{0.056} & $2874(99.8)$ & $6(0.2)$ & \multirow[t]{2}{*}{1.000} & $2493(85.6)$ & $420(14.4)$ & \multirow[t]{2}{*}{0.748} \\
\hline & Smoker & $41(59.4)$ & $28(40.6)$ & & $65(94.2)$ & $4(5.8)$ & & $69(100)$ & $0(0)$ & & $60(87)$ & $9(13)$ & \\
\hline \multirow{4}{*}{$\begin{array}{l}\text { DOIP } \\
\text { (months) }\end{array}$} & $\leq 6$ & $774(59.1)$ & $536(40.9)$ & \multirow{4}{*}{0.404} & $1288(98.4)$ & $21(1.6)$ & \multirow{4}{*}{0.291} & 1294(99.8) & $3(0.2)$ & \multirow{4}{*}{0.447} & $1134(86.6)$ & $176(13.4)$ & \multirow{4}{*}{0.408} \\
\hline & $>6-24$ & $414(58.7)$ & 291(41.3) & & $688(97.6)$ & $17(2.4)$ & & $695(100)$ & $0(0)$ & & $593(84.1)$ & $112(15.9)$ & \\
\hline & $>24-120$ & $464(60.1)$ & $308(39.9)$ & & $753(97.5)$ & $19(2.5)$ & & $760(99.6)$ & $3(0.4)$ & & $656(85)$ & $116(15)$ & \\
\hline & $>120$ & $127(65.1)$ & $68(34.9)$ & & $189(96.9)$ & $6(3.1)$ & & $194(100)$ & $0(0)$ & & $170(87.2)$ & $25(12.8)$ & \\
\hline \multirow{4}{*}{$\begin{array}{l}\text { Type of } \\
\text { combination } \\
\text { DMARD }\end{array}$} & $\begin{array}{l}\text { Single } \\
\text { DMARD }\end{array}$ & $269(61.7)$ & $167(38.3)$ & \multirow{4}{*}{0.478} & $426(97.7)$ & $10(2.3)$ & \multirow{4}{*}{0.931} & $431(99.5)$ & $2(0.5)$ & \multirow{4}{*}{0.217} & $375(86)$ & $61(14)$ & \\
\hline & $\begin{array}{l}\text { Double } \\
\text { DMARD }\end{array}$ & $1207(58.8)$ & $846(41.2)$ & & $2009(97.9)$ & $44(2.1)$ & & 2032(99.9) & $3(0.1)$ & & $1750(85.2)$ & $303(14.8)$ & \\
\hline & $\begin{array}{c}\text { Triple } \\
\text { DMARD }\end{array}$ & $295(61.7)$ & 183(38.3) & & $468(98.1)$ & $9(1.9)$ & & $465(99.8)$ & $1(0.2)$ & & $415(86.8)$ & $63(13.2)$ & 0.831 \\
\hline & $\begin{array}{l}\text { Four } \\
\text { DMARD }\end{array}$ & $8(53.3)$ & $7(46.7)$ & & $15(100)$ & $0(0)$ & & $15(100)$ & $0(0)$ & & $13(86.7)$ & 2(13.3) & \\
\hline TOD (months) & Median & 60 & 48 & 0171 & 48 & 60 & 0.434 & 54 & 42 & 0.360 & 48 & 56 & 0353 \\
\hline 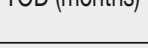 & Range & $0.5-480$ & $0.5-492$ & 0.117 & $0.5-492$ & $3-420$ & 0.704 & $0.5-492$ & $0.7-96$ & 0.000 & $0.5-492$ & $0.5-420$ & 0.00 \\
\hline DOF (months) & Median & 24 & 24 & 072 & 24 & 24 & 0774 & 24 & 11.50 & 0178 & 24 & 21 & 0.076 \\
\hline Dor (intionis) & Range & $0-360$ & $0-484$ & 0.12 & $0-484$ & $0-240$ & 0.114 & $0-484$ & $0-30$ & 0.110 & $0-484$ & $0-360$ & 0.010 \\
\hline $\begin{array}{l}\text { Total group } \\
\text { size }\end{array}$ & & $1779(59.7)$ & $1203(40.3)$ & & $2918(97.9)$ & $63(2.1)$ & & $2943(99.8)$ & $6(0.2)$ & & $2553(85.6)$ & $429(14.4)$ & \\
\hline
\end{tabular}

PD, pulmonary diseases; CVD, cardiovascular diseases; DM, diabetes mellitus; DOIP, duration of illness prior; TOD, total duration of disease; DOF, duration of follow-up with rheumatologist. *Variables given as number (percentage) or median (range). Mann-Whitney U test for continuous variables and chi-square for categorical variables $p$ value are presented. 
Table II - Descriptive characteristics of rheumatoid arthritis patients with hypertension, hypercholesterolemia and thyroid illness.

\begin{tabular}{|c|c|c|c|c|c|c|c|c|c|c|}
\hline \multirow{2}{*}{ Variables* } & \multirow{2}{*}{ Groups } & \multicolumn{3}{|c|}{ HTN $(n=2980)$} & \multicolumn{3}{|c|}{ Hypercholestrolemia ( $n=1827)$} & \multicolumn{3}{|c|}{ Thyroid illness (n=1992) } \\
\hline & & No & Yes & $p$ value & No & Yes & $p$ value & No & Yes & $p$ value \\
\hline \multirow{5}{*}{$\begin{array}{l}\text { Age groups } \\
\text { (years) }\end{array}$} & $<30$ & $186(82.3)$ & $40(17.7)$ & \multirow{5}{*}{$<0.001$} & 133(93) & $10(7)$ & \multirow{5}{*}{0.035} & $125(78.1)$ & $35(21.9)$ & \multirow{5}{*}{0.666} \\
\hline & $30-39$ & $402(86.3)$ & 64(13.7) & & 292(97.3) & $8(2.7)$ & & $265(80.8)$ & $63(19.2)$ & \\
\hline & $40-49$ & $634(82.6)$ & $134(17.4)$ & & $445(96.1)$ & $18(3.9)$ & & $426(82.7)$ & $89(17.3)$ & \\
\hline & $50-59$ & $664(76.7)$ & 202(23.3) & & 495(93.8) & $33(6.3)$ & & $466(81.5)$ & $106(18.5)$ & \\
\hline & $\geq 60$ & $476(72.8)$ & $178(27.2)$ & & $365(92.9)$ & $28(7.1)$ & & $346(83)$ & $71(17)$ & \\
\hline \multirow{2}{*}{ Gender } & Male & $373(80.4)$ & $91(19.6)$ & \multirow{2}{*}{0.515} & $249(90.9)$ & $25(9.1)$ & \multirow{2}{*}{0.002} & $253(86.3)$ & $40(13.7)$ & \multirow{2}{*}{0.027} \\
\hline & Female & $1989(79.1)$ & $527(20.9)$ & & $1481(95.4)$ & $72(4.6)$ & & $1375(80.9)$ & $324(19.1)$ & \\
\hline \multirow{2}{*}{$\begin{array}{l}\text { Smoking } \\
\text { status }\end{array}$} & $\begin{array}{l}\text { Non- } \\
\text { Smoker }\end{array}$ & $2303(79.1)$ & $608(20.9)$ & \multirow{2}{*}{0.195} & $1694(94.8)$ & $92(5.2)$ & \multirow[t]{2}{*}{0.063} & 1598(81.9) & $354(18.1)$ & \multirow{2}{*}{0.266} \\
\hline & Smoker & $59(85.5)$ & $10(14.5)$ & & $36(87.8)$ & $5(12.2)$ & & $30(75)$ & $10(25)$ & \\
\hline \multirow{4}{*}{$\begin{array}{l}\text { DOIP } \\
\text { (months) }\end{array}$} & $\leq 6$ & $1035(79.1)$ & $274(20.9)$ & \multirow{4}{*}{0.263} & 719(93.7) & $48(6.3)$ & \multirow{4}{*}{0.026} & $681(80)$ & $170(20)$ & \multirow{4}{*}{0.356} \\
\hline & $>6-24$ & $565(80.3)$ & $139(19.7)$ & & $429(97.3)$ & $12(2.7)$ & & $406(82.5)$ & $86(17.5)$ & \\
\hline & $>24-120$ & $599(77.6)$ & $173(22.4)$ & & $458(93.5)$ & $32(6.5)$ & & $432(83.7)$ & $84(16.3)$ & \\
\hline & $>120$ & $163(83.6)$ & $32(16.4)$ & & 124(96.1) & $5(3.9)$ & & $109(82)$ & $24(18)$ & \\
\hline \multirow{4}{*}{$\begin{array}{l}\text { Type of } \\
\text { combination } \\
\text { DMARD }\end{array}$} & $\begin{array}{c}\text { Single } \\
\text { DMARD }\end{array}$ & $349(80)$ & $87(20)$ & \multirow{4}{*}{0.803} & $270(96.8)$ & $9(3.2)$ & \multirow{4}{*}{0.308} & $270(84.4)$ & $50(15.6)$ & \multirow{4}{*}{0.063} \\
\hline & $\begin{array}{l}\text { Double } \\
\text { DMARD }\end{array}$ & $1617(78.8)$ & $435(21.2)$ & & $1254(94.4)$ & $74(5.6)$ & & 1158(82) & $255(18)$ & \\
\hline & $\begin{array}{c}\text { Triple } \\
\text { DMARD }\end{array}$ & $383(80.3)$ & $94(19.7)$ & & $201(93.5)$ & $14(6.5)$ & & 196(77.8) & $56(22.2)$ & \\
\hline & $\begin{array}{c}\text { Four } \\
\text { DMARD }\end{array}$ & $13(86.7)$ & $2(13.3)$ & & $5(100)$ & $0(0)$ & & $4(57.1)$ & $3(42.9)$ & \\
\hline \multirow{2}{*}{$\begin{array}{l}\text { TOD } \\
\text { (months) }\end{array}$} & Median & 48 & 50 & \multirow{2}{*}{0.996} & 48 & 48 & \multirow{2}{*}{0.616} & 48 & 48 & \multirow{2}{*}{0.333} \\
\hline & Range & $0.5-484$ & $0.5-492$ & & $0.5-492$ & $0.7-420$ & & $0.5-492$ & $0.7-484$ & \\
\hline \multirow{2}{*}{$\begin{array}{l}\text { DOF } \\
\text { (months) }\end{array}$} & Median & 24 & 24 & \multirow{2}{*}{0.542} & 24 & 12 & \multirow{2}{*}{0.269} & 24 & 24 & 0877 \\
\hline & Range & $0-484$ & $0-384$ & & $0-360$ & $0-360$ & & $0-360$ & $0-484$ & 0.871 \\
\hline $\begin{array}{l}\text { Total group } \\
\text { size }\end{array}$ & & $2362(79.3)$ & $618(20.7)$ & & $1730(94.7)$ & $97(5.3)$ & & $1628(81.7)$ & $364(18.3)$ & \\
\hline
\end{tabular}

HTN, hypertension; DOIP, duration of illness prior; TOD, total duration of disease; DOF, duration of follow-up with rheumatologist. *Variables given as number (percentage) or median (range). Mann-Whitney U test for continuous variables and chi-square for categorical variables $p$ value are presented.

gard to age groups was noted in subjects with presence of comorbidity, PD, DM, HTN and hypercholesterolemia. Among the age groups, RA patients with $\geq 60 \mathrm{yrs}$ had increased presence of any comorbidity $(47.4 \%)$, PD (3.4\%), DM (18.7\%) and HTN (27.2\%). Percentage-wise, the higher prevalence of hypercholesterolemia was in $\geq 60 \mathrm{yrs}(7.1 \%)$ and $<30 \mathrm{yrs}(7 \%)$ age groups. The CVD and thyroid illness was more frequent in 30-39 yrs and $<30$ yrs age groups $(21.9 \%)$ respectively. PD patients also showed a trend towards significance $(\mathrm{p}=0.056)$ for smoking history. In addition to age, gender and DOIP also differed significantly between groups with and without hypercholesterolemia. The frequency of hypercholesterolemia was higher in males $(9.1 \%)$ compared to females $(4.6 \%)$. Patients with $>2-10$ yrs DOIP $(6.5 \%)$ and $\leq 6$ DOIP $(6.3 \%)$ had increased incidence of hypercholesterolemia. Gender was significantly associated for thyroid disease. The frequency of thyroid disease was higher in females $(19.1 \%)$ than male patients $(13.7 \%)$. The remaining variables did not 
differ between the groups for these comorbidities. However, no significant difference for any of the assessed variables was noted for subjects with CVD.

The univariate logistic regression for the presence of comorbidity and DM showed that age and DOIP were within the cut-off $p$ value $\leq 0.2$ for inclusion in multivariate analysis. The variables considered for the diverse comorbidities were: age, smok- ing status and DOIP for PD; age, smoking status and DOF for HTN; age, gender, smoking status, and DOIP for hypercholesterolemia; and gender, DOIP and type of DMARD combination for thyroid disease. Multivariate analysis was not performed for CVD, since the univariate result had only DOF within the cut-off $p$ value $\leq 0.2$. The TOD was not included in multivariate analysis, since the variable showed mul-

Table III - Multivariate logistic regression analysis on factors related to the presence of comorbidity, pulmonary diseases, and diabetes mellitus in rheumatoid arthritis patients.

\begin{tabular}{|c|c|c|c|c|}
\hline Comorbidities & Variables & Odds ratio & $95 \%$ confidence interval & $p$ value \\
\hline \multirow{10}{*}{$\begin{array}{l}\text { Presence of } \\
\text { comorbidity }\end{array}$} & Age groups (years) & & $x^{2}+x^{2}$ & $<0.001$ \\
\hline & $30-39$ & 0.776 & $0.556-1.083$ & 0.136 \\
\hline & $40-49$ & 1.011 & $0.744-1.374$ & 0.946 \\
\hline & $50-59$ & 1.301 & $0.962-1.760$ & 0.088 \\
\hline & $\geq 60$ & 1.559 & $1.141-2.130$ & 0.005 \\
\hline & DOIP & $\sqrt{x}$ & & 0.135 \\
\hline & $>6-24$ & 1.030 & $0.854-1.242$ & 0.757 \\
\hline & $>24-120$ & 0.941 & $0.784-1.130$ & 0.514 \\
\hline & $>120$ & 0.702 & $0.511-0.965$ & 0.029 \\
\hline & Constant & 0.605 & & $<0.001$ \\
\hline \multirow{11}{*}{ PD } & Age groups (years) & & & 0.084 \\
\hline & $30-39$ & 0.342 & $0.076-1.546$ & 0.163 \\
\hline & $40-49$ & 1.028 & $0.336-3.147$ & 0.961 \\
\hline & $50-59$ & 1.145 & $0.383-3.427$ & 0.808 \\
\hline & $\geq 60$ & 1.760 & $0.593-5.224$ & 0.309 \\
\hline & Smoking status (smoker) & 2.733 & $0.955-7.820$ & 0.061 \\
\hline & DOIP & & & 0.421 \\
\hline & $>6-24$ & 1.551 & $0.811-2.966$ & 0.185 \\
\hline & $>24-120$ & 1.537 & $0.819-2.885$ & 0.181 \\
\hline & $>120$ & 1.722 & $0.681-4.357$ & 0.251 \\
\hline & Constant & 0.014 & & $<0.001$ \\
\hline \multirow{10}{*}{ DM } & Age groups (years) & & & 0.001 \\
\hline & $30-39$ & 0.848 & $0.509-1.412$ & 0.526 \\
\hline & $40-49$ & 1.261 & $0.798-1.994$ & 0.320 \\
\hline & $50-59$ & 1.356 & $0.864-2.130$ & 0.186 \\
\hline & $\geq 60$ & 1.814 & $1.149-2.863$ & 0.011 \\
\hline & DOIP & & & 0.271 \\
\hline & $>6-24$ & 1.242 & $0.959-1.607$ & 0.100 \\
\hline & $>24-120$ & 1.119 & $0.868-1.444$ & 0.386 \\
\hline & $>120$ & 0.862 & $0.548-1.355$ & 0.519 \\
\hline & Constant & 0.119 & & $<0.001$ \\
\hline
\end{tabular}

DM, diabetes mellitus; PD, pulmonary diseases; DOIP, duration of illness prior. 
ticollinearity with DOIP and DOF. The independent variables were entered by simultaneous entry method for multivariate logistic regression analysis.

The results of multivariate logistic regression analysis are given in Tables III and IV. Difference in age groups has been identified as a significant independent predictor for presence of comorbidity. The age group $\geq 60$ years demonstrated a $56 \%$ increased likelihood of comorbidity than the reference group of $<30$ years. The probability of comorbidity reduced with DOIP. The subgroup with $>120$ months of DOIP had $30 \%$ less likelihood of comorbidity than the DOIP group of $\leq 6$ months. A statistically significant association for age with DM and HTN has been noted. The corresponding increases in likelihood of having DM and HTN were $81 \%$ and $72 \%$ in the

Table IV - Multivariate logistic regression analysis on factors related to hypertension, hypercholesterolemia and thyroid disease in rheumatoid arthritis patients.

\begin{tabular}{|c|c|c|c|c|}
\hline Comorbidities & Variables & Odds ratio & 95\% Confidence interval & $p$ value \\
\hline \multirow{8}{*}{ HTN } & Age groups in years & & & $<0.001$ \\
\hline & $30-39$ & 0.739 & $0.480-1.139$ & 0.170 \\
\hline & $40-49$ & 0.978 & $0.661-1.447$ & 0.911 \\
\hline & $50-59$ & 1.403 & $0.960-2.050$ & 0.081 \\
\hline & $\geq 60$ & 1.721 & $1.167-2.539$ & 0.006 \\
\hline & Smoking status (Smoker) & 0.601 & $0.304-1.188$ & 0.143 \\
\hline & DOF & 1.001 & 0.999-1.002 & 0.438 \\
\hline & Constant & 0.212 & 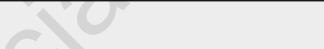 & $<0.001$ \\
\hline \multirow{12}{*}{ Hypercholesterolemia } & Age groups in years & & 3 & 0.055 \\
\hline & $30-39$ & 0.349 & 0.134-0.911 & 0.031 \\
\hline & $40-49$ & 0.499 & $0.223-1.119$ & 0.092 \\
\hline & $50-59$ & 0.839 & $0.399-1.763$ & 0.642 \\
\hline & $\geq 60$ & 0.903 & $0.421-1.936$ & 0.793 \\
\hline & Gender (Female) & 0.570 & $0.337-0.964$ & 0.036 \\
\hline & Smoking status (Smoker) & 1.877 & $0.648-5.432$ & 0.246 \\
\hline & DOIP & & & 0.022 \\
\hline & $>6-24$ & 0.404 & $0.211-0.774$ & 0.006 \\
\hline & $>24-120$ & 1.070 & $0.671-1.707$ & 0.775 \\
\hline & $>120$ & 0.568 & $0.219-1.470$ & 0.243 \\
\hline & Constant & 0.148 & & $<0.001$ \\
\hline \multirow{10}{*}{ Thyroid disease } & Gender (Female) & 1.487 & $1.040-2.125$ & 0.030 \\
\hline & Type of Combination DMARD & & & 0.076 \\
\hline & Double DMARD & 1.215 & $0.872-1.693$ & 0.250 \\
\hline & Triple DMARD & 1.545 & $1.010-2.363$ & 0.045 \\
\hline & Four DMARD & 4.458 & $0.959-20.725$ & 0.057 \\
\hline & DOIP & & & 0.293 \\
\hline & $>6-24$ & 0.833 & $0.624-1.112$ & 0.215 \\
\hline & $>24-120$ & 0.767 & $0.574-1.024$ & 0.072 \\
\hline & $>120$ & 0.850 & $0.529-1.367$ & 0.504 \\
\hline & Constant & 0.146 & & $<0.001$ \\
\hline
\end{tabular}

HTN, hypertension; DMARD, disease-modifying antirheumatic drugs; DOIP, duration of illness prior; DOF, duration of follow-up with rheumatologist. 
$\geq 60$ years age group compared to the reference group. Though there was a decrease in likelihood of comorbidity after 2 years of DOIP, the influence was not significant with DM. Smoking history and DOF were not associated with HTN.

Patients with hypercholesterolemia showed statistically significant association with age, gender, and DOIP. Decrease in likelihood of hypercholesterolemia was noted with increase in age, with subjects between $30-39$ years $65 \%$ less likely than the reference group. Female subjects demonstrated $43 \%$ less likelihood of having dyslipidemia than males. RA patients with DOIP $>6-24$ months were $60 \%$ less likely to have hypercholesterolemia than $\leq 6$ months group. Smokers had an OR of 1.9 of having dyslipidemia compared to non-smokers; however, smoking had 95\% CI crossing 1.

The likelihood of thyroid disease in female RA patients was $49 \%$ more than in males. The RA patients on triple and four DMARD combinations were 1.55 and 4.46 times more likely to have thyroid disease, respectively, compared to subjects on single DMARD therapy. DOIP was not associated with thyroid disease.

Overall incidence of PD and depression were found to be $2.1 \%$ and $0.03 \%$ respectively. PD did not show association with any of the independent variables, except smoking (OR: 2.7; 95\% CI: 0.955-7.820), but the association was not statistically significant.

\section{DISCUSSION AND CONCLUSIONS}

In the present study, the prevalence of comorbidities in RA patients in south Indian population was observed to be $40.3 \%$. The commonly observed comorbidities were HTN (20.7\%), DM (14.4\%) and thyroid disease $(18.3 \%)$. Other comorbidities like hypercholesterolemia, PD, CVD and depression were prevalent in $\leq 5 \%$ of the population. The overall presence of comorbidity increased with age and reduced with the DOIP. Increased association of comorbidities with patients in higher age groups is found in similar studies. The reduced association with DOIP could be due to the occurrence of less severe disease in RA patients with >120 months and their late visit to the rheumatologist (maybe due to low intensity of disease). These patients have less likelihood of comorbidity compared to patients with severe disease course (13-15). Prevalence of comorbidities like HTN and DM was lower in the current study subjects compared to similar studies reported from other parts of the world. Prevalence of HTN was found to be maximum in $\geq 60$ years $(27.2 \%)$, followed by $23.3 \%$ in $50-59$ years, and $13-17 \%$ in patients of $<49$ years. The corresponding prevalence of HTN noted by Al-Bishri et al. in their Comorbidities in Rheumatoid Arthritis (COMORA) study were $35.9 \%$ (mean age $53.3 \pm 11.3, \mathrm{n}=340$ ) and $40.4 \%$ (mean age $56 \pm 13, \mathrm{n}=4586)(2$, 16). Moreover, Panoulas et al. observed $70 \%$ (mean age $61.56 \pm 12.02, \quad n=400$ ) prevalence of HTN in RA patients (17). The prevalence of HTN in the present RA population appeared equal or higher when compared to reported studies of the general population in India. The Chennai Urban Population Study (CUPS) had reported $21.1 \%$ (age $\geq 20$ years, $n=1262$ ) prevalence of HTN, while the age-standardized prevalence was $17.0 \%$ (18). Another south Indian study titled the Chennai Urban Rural Epidemiological Study (CURES-52) had reported $20 \%$ overall presence of HTN and $6.6 \%$ self-reported prevalence (19). In contrast to the aforementioned studies, which had adopted active detection methods for diagnosing HTN, the present study has relied only on self-reported data collection. Applying the rule of half to the current study, we can expect a moderately higher prevalence of HTN in RA patients. The rule of halves theory suggests that half of the prevalent cases are not known or diagnosed, half of those are not treated and half of those treated are not controlled (20).

Al-Bishri et al. had reported DM as one of the common comorbidities $(30.9 \%)$ in RA patients $(n=340)(16)$. COMORA reported $14 \%$ prevalence of DM in RA patients worldwide (2). The Indian study on the general population, CURES-17 study had found $14.3 \%$ (Age $\geq 20$ years, 
$\mathrm{n}=26,001)$ as the age-standardized prevalence of DM in the general population of Chennai, India. Age-wise distribution of DM in CURES-17 was: 20-29 years: $6.6 \%$, 30-39 years: $25.2 \%, 40-49$ years: $30 \%, 50-$ 59 years: $24.9 \%, 60-69$ years: $10.4 \%,>69$ years: $2.5 \%$ (1). The corresponding prevalence of DM reported in the multicity study by Ramachandran et al., involving six urban cities in India, were $13.5 \%$ in Chennai and $12.4 \%$ in Bangalore (age $\geq 20$ years, $\mathrm{n}=11,216)$ (21). The prevalence of overall and self-reported type II DM, noted by Rao et al., in coastal Karnataka were $16 \%$ and $11 \%(n=1239)$ respectively (22). The $14.4 \%$ prevalence of DM noted in the present study is comparable to the aforementioned South Indian studies conducted on the general population.

The systematic literature review conducted by Wasco et al. suggested reduction in prevalence of DM in patients with RA (23). The present study indicates the likelihood of diabetes to be higher in the age group $>60$ years (OR: 1.814). Whereas incidence reduced after a peak at 50 years of age in the general population, as per the CURES 17 study (24). However, the present prevalence is significantly lower when compared to international studies involving RA patients. The mean age of the RA patients reported in certain international studies is a few years higher than in our study.

The prevalence of thyroid disease was higher $(18.3 \%)$ in the present study subjects, with higher preponderance in women than men, when compared to the general population in south India and international studies. Furthermore, the disease was more prevalent in young RA patients between 30 $39(21.9 \%)$ of age. The multi-center, epidemiological study conducted in eight major cities in India by Unnikrishnan et. al. had observed the prevalence of hypothyroidism in the general population to be $10.95 \%$, out of which $7.48 \%$ was self-reported condition (mean age 46 $\pm 14.68, \mathrm{n}=5360$ ) (25). The retrospective study by Mosli et al., involving $151 \mathrm{RA}$ subjects, had reported the prevalence of hypothyroidism to be $4 \%$ $(n=151)$ (26). The prevalence of thyroid disease reported by Espiño-Lorenzo et al. was $13 \%$ (27). The prevalence of thyroid disorders noted in a Colombian cohort of RA patients was $9.8 \%$ (mean age 51.92, $\mathrm{n}=800$ ) with higher levels of thyroid antibodies (28). The patients with thyroid disease required a higher number of DMARDs, which could be inferred as increased probability of thyroid disease with increasing number of DMARDs used [higher for four DMARD combination (42.9\%, OR: 4.458) compared to triple $(22.2 \%)$, double $(18 \%)$ and single DMARDs (15.6\%)]. Since the increase in DMARDs does not confer any causative effect on thyroid disease, the association can be interpreted as that the need for DMARD combination therapy is directly associated with the presence of thyroid disease.

The $5.3 \%$ prevalence of hypercholesterolemia noted in the present study was significantly lower than those reported in the general population from India and international studies involving RA patients. Joshi et al. reported $18.3 \%(n=16,607)$ prevalence of hypercholesterolemia among the general population of Tamil Nadu (29). Moreover, the prevalence was higher in patients with early RA (6-24 months). The prevalence of hypercholesterolemia in the COMORA study $(n=4586)$ in RA patients was $31.7 \%$ (2). Similar to this finding, Espiño-Lorenzo et al. had reported $33 \%$ prevalence of hypercholesterolemia in RA patients (27). The current study has considered only the patients who had undergone the test within the 6-month period of the date of screening. This could be the reason for the underestimation of the prevalence. Another reason could be that a larger proportion of the patients was on hydroxychloroquine, which has a cholesterol-lowering effect (30).

The meta-analysis by Boyer et al. reported that the prevalence of hypercholesterolemia did not differ when compared to the controls (OR: 0.84) (31). It had also been noted that the classical risk factors of patients with RA and controls were similar, but the cholesterol levels were lesser in the former group. The prevalence of hypercholesterolemia noted by the Outcome of Rheumatoid Arthritis Longitudinal Evaluation (ORALE) study involving RA subjects 
was $22.9 \%$, whereas the prevalence in the general population reported by the San Antonio Heart Study (SAHS) was $48.7 \%$ (32). Landewé et al. demonstrated a strong elevation from low baseline cholesterol levels in RA patients at 16 weeks of therapy and stabilization at 56 weeks (33). As expected, the likelihood of hypercholesterolemia was higher in smokers (OR: 1.877). Decrease in likelihood of hypercholesterolemia with increase in age noted in the current study could be due to hydroxychloroquine therapy (34-37). Moreover, these patients had decreased likelihood of hypercholesterolemia with increase in DOIP, suggesting that the reduction in hypercholesterolemia may be because of less severe RA.

As per the literature evidence, the prevalence of CVD in RA patients varies in different countries (1\% in Morocco and 17\% in Hungary) (2). The disease prevalence noted in the present study was $0.2 \%$. The low prevalence of cardiovascular morbidity could be due to the younger age of our population and the adoption of self-reporting for patient recruitment rather than proactive disease screening. Low incidence of hypercholesterolemia and hypertension found could have contributed to low prevalence of CVD in the current study.

Depression is a commonly observed comorbidity in RA patients; however, its prevalence varies across the world (2\% in Morocco, $33 \%$ in USA) (2). In the present study, the criterion for diagnosis of depression was confirmation by a psychiatrist and it should be severe enough to need management with drugs. This may be the reason for the reduced prevalence of depression in our study. Increase in likelihood of bronchial asthma and COPD was noted with increase in age and constant with duration of illness.

The study has achieved its main objective of estimating prevalence of comorbidities and their association and its association with various demographic and clinical factors. In addition to the adequate size of the population considered, the subjects were recruited from both academic and non-academic practice. It is noteworthy that the sample size also represents both urban and rural subjects, and across all the income groups proportional to the population economics of the state. The adoption of cluster design of sampling and the power of the study add to the key findings. However, non-inclusion of patients on biologics therapy in the study may have led to patient selection bias, as such patients usually have more severe disease. The detection of comorbidity based on self-reporting and previously diagnosed status, which fact may could have contributed to the under-reporting of the prevalence. Lack of data was a concern in some subjects, since the status of thyroid, lipid test etc. was not available at the time of screening. However, the high number of patients is expected to compensate for these limitations. To the best of our knowledge, there is no study from India documenting the prevalence of all the comorbidities in a single population cohort. The overall incidence of comorbidities, except for DM, appears to be higher in RA than age- and sex-matched general south Indian population. The prevalence of comorbidities in RA patients is around $40 \%$. HTN, DM and thyroid disease are the commonly noted comorbidities. There is increased prevalence of thyroid disease in female patients. The present study, describing the pattern of prevalence of comorbidities in different age groups, could be beneficial in optimizing the management strategies and to maximize patient benefit from early identification and intervention.

Funding: this work was supported by Indian Rheumatology Association-Karnataka Chapter.

Conflict of interest: the authors declare no conflict of interest.

\section{REFERENCES}

1. Michaud K, Wolfe F. Comorbidities in rheumatoid arthritis. Best Pract Res Clin Rheumatol. 2007; 21: 885-906.

2. Dougados M, Soubrier M, Antunez A, et al. Prevalence of comorbidities in rheumatoid arthritis and evaluation of their monitoring: results of an international, cross-sectional study (COMORA). Ann Rheum Dis. 2014; 73: 62-8. 
3. Grøn KL, Ornbjerg LM, Hetland ML, et al. The association of fatigue, comorbidity burden, disease activity, disability and gross domestic product in patients with rheumatoid arthritis. Results from 34 countries participating in the Quest-RA program. Clin Exp Rheumatol. 2014; 32: 869-77.

4. Parodi M, Bensi L, Maio T, et al. Comorbidities in rheumatoid arthritis: analysis of hospital discharge records. Reumatismo. 2005; 57 : 154-60.

5. Mikuls TR, Saag KG. Comorbidity in rheumatoid arthritis. Rheum Dis Clin North Am. 2001; 27: 283-303.

6. Gabriel SE, Crowson CS, Kremers HM, et al. Survival in rheumatoid arthritis: a populationbased analysis of trends over 40 years. Arthritis Rheum. 2003; 48: 54-8.

7. Wasserman AM. Diagnosis and management of rheumatoid arthritis. Am Fam Physician. 2011; 84: 1245-52.

8. Villaverde V, Loza E, Ortiz A, et al. FRI0102 A systematic literature review of the impact of comorbidity on quality of life and costs in patients with rheumatoid arthritis. The Gecoar Study. Ann Rheum Dis. 2014; 73: 418.

9. MacLean CH, Louie R, Leake B, et al. Quality of care for patients with rheumatoid arthritis. JAMA 2000; 284: 984-92.

10. Listing J, Gerhold K, Zink A. The risk of infections associated with rheumatoid arthritis, with its comorbidity and treatment. Rheumatology (Oxford). 2013; 52: 53-61.

11. Aletaha D, Neogi T, Silman AJ, et al. 2010 Rheumatoid arthritis classification criteria: an American College of Rheumatology/European League Against Rheumatism collaborative initiative. Arthritis Rheum. 2010; 62: 2569-81.

12. National Cholesterol Education Program (NCEP) Expert Panel on Detection, Evaluation, and Treatment of High Blood Cholesterol in Adults (Adult Treatment Panel III). Third Report of the National Cholesterol Education Program (NCEP) Expert Panel on Detection, Evaluation, and Treatment of High Blood Cholesterol in Adults (Adult Treatment Panel III) final report. Circulation. 2002; 106: 3143-421.

13. Ranganath VK, Maranian P, Elashoff DA, et al. Comorbidities are associated with poorer outcomes in community patients with rheumatoid arthritis. Rheumatology. 2013; 27: ket224.

14. van Onna M, Boonen A. The challenging interplay between rheumatoid arthritis, ageing and comorbidities. BMC Musculoskelet Disord. 2016; 17: 184.

15. Norton S, Koduri G, Nikiphorou E, et al. A study of baseline prevalence and cumulative incidence of comorbidity and extra-articular manifestations in RA and their impact on outcome. Rheumatology. 2013; 52: 99-110.
16. Al-Bishri J, Attar S, Bassuni N, et al. Comorbidity profile among patients with rheumatoid arthritis and the impact on prescriptions trend. Clin Med Insights Arthritis Musculoskelet Disord. 2013; 6: 11-8.

17. Panoulas VF, Douglas KMJ, Milionis HJ, et al. Prevalence and associations of hypertension and its control in patients with rheumatoid arthritis. Rheumatology (Oxford). 2007; 46: 1477-82.

18. Shanthirani CS, Pradeepa R, Deepa R, et al. Prevalence and risk factors of hypertension in a selected South Indian population-the Chennai Urban Population Study. J Assoc Physicians India. 2003; 51: 20-7.

19. Mohan V, Deepa M, Farooq S, et al. Prevalence, awareness and control of hypertension in Chennai--The Chennai Urban Rural Epidemiology Study (CURES-52). J Assoc Physicians India. 2007; 55: 326-32.

20. Deepa R, Shanthirani CS, Pradeepa R, Mohan $\mathrm{V}$. Is the "rule of halves" in hypertension still valid? - Evidence from the Chennai Urban Population Study. J Assoc Physicians India. 2003; 51: 153-7.

21. Ramachandran A, Snehalatha C, Kapur A, et al. High prevalence of diabetes and impaired glucose tolerance in India: National Urban Diabetes Survey. Diabetologia. 2001; 44: 1094-101.

22. Rao CR, Kamath VG, Shetty A, Kamath A. A study on the prevalence of type 2 diabetes in coastal Karnataka. Int J Diabetes Dev Ctries. 2010; 30: 80-5.

23. Wasko MC, Kay J, Hsia EC, Rahman MU. Diabetes mellitus and insulin resistance in patients with rheumatoid arthritis: risk reduction in a chronic inflammatory disease. Arthritis Care Res (Hoboken). 2011; 63: 512-21.

24. Mohan V, Deepa M, Deepa R, et al. Secular trends in the prevalence of diabetes and impaired glucose tolerance in urban South India - the Chennai Urban Rural Epidemiology Study (CURES-17). Diabetologia. 2006; 49: 1175-8.

25. Unnikrishnan AG, Kalra S, Sahay RK, et al. Prevalence of hypothyroidism in adults: An epidemiological study in eight cities of India. Indian J Endocrinol Metab. 2013; 17: 647-52.

26. Mosli H, Attar MS. Prevalence and patterns of thyroid dysfunction in patients with rheumatoid arthritis. Open Endocrinol J. 2014; 7: 1-5.

27. Espiño-Lorenzo P, Manrique-Arija S, Ureña I, et al. Baseline comorbidities in patients with rheumatoid arthritis who have been prescribed biological therapy: a case control study. Reumatol Clin. 2013; 9: 18-23.

28. Cárdenas Roldán J, Amaya-Amaya J, Castellanos-de la Hoz J, et al. Autoimmune thyroid disease in rheumatoid arthritis: a global perspective. Arthritis 2012; 2012: 864907. 
29. Joshi SR, Anjana RM, Deepa M, et al. Prevalence of dyslipidemia in urban and rural India: the ICMR-INDIAB study. PLoS One. 2014; 9: e96808.

30. Kerr G, Aujero M, Richards J, et al. Associations of hydroxychloroquine use with lipid profiles in rheumatoid arthritis: pharmacologic implications. Arthritis Care Res (Hoboken). 2014; 66: 1619-26.

31. Boyer J-F, Gourraud P-A, Cantagrel A, et al. Traditional cardiovascular risk factors in rheumatoid arthritis: a meta-analysis. Joint Bone Spine. 2011; 78: 179-83.

32. del Rincón ID, Williams K, Stern MP, et al. High incidence of cardiovascular events in a rheumatoid arthritis cohort not explained by traditional cardiac risk factors. Arthritis Rheum. 2001; 44: 2737-45.

33. Boers M, Nurmohamed MT, Doelman CJA, et al. Influence of glucocorticoids and disease activity on total and high density lipoprotein cholesterol in patients with rheumatoid arthritis. Ann Rheum Dis. 2003; 62: 842-5.
34. Morris SJ, Wasko MCM, Antohe JL, et al. Hydroxychloroquine use associated with improvement in lipid profiles in rheumatoid arthritis patients. Arthritis Care Res. 2011; 63: 530-4.

35. Wallace DJ, Metzger AL, Stecher VJ, et al. Cholesterol-lowering effect of hydroxychloroquine in patients with rheumatic disease: reversal of deleterious effects of steroids on lipids. Am J Med. 1990; 89: 322-6.

36. Hage MP, Al-Badri MR, Azar ST. A favorable effect of hydroxychloroquine on glucose and lipid metabolism beyond its anti-inflammatory role. Ther Adv Endocrinol Metab. 2014; 5: 77-85.

37. Restrepo JF, del Rincón I, Molina E, et al. Use of hydroxychloroquine associated with improved lipid profile in rheumatoid arthritis patients [Internet]. ACR Meeting Abstracts. [cited 2017 Jan 13]. Available from: http://acrabstracts.org/abstract/useof-hydroxychloroquine-as sociated-withimproved-lipid-profile-in-rheumatoid-arthritis-patients/ 